\title{
An Analysis of the Coupling Between Temperature and Thermal Stress of Disc Brakes Based on Finite Element
}

\author{
Min Wen \\ Faculty of Civil and Architectural Engineering, Nanchang Institute of Technology, Nanchang 330099, China
}

Corresponding Author Email: 2008994073@nit.edu.cn

https://doi.org/10.18280/ijht.390616

Received: 7 September 2021

Accepted: 2 December 2021

\section{Keywords:}

disc brake, temperature field, thermal stress, finite element analysis

\begin{abstract}
Disc brakes have been more widely used in recent years due to its many merits such as fast heat absorption and dissipation, and resistance to water fade. Since it's difficult to describe the failure of brakes under complex working conditions in only a few times of thermalstructural coupling simulations, this paper analyzed the coupling between temperature and thermal stress of disc brakes under multiple continuous braking conditions. At first, a 3D model of bus disc brake was built in ABAQUS, and its braking motion and dynamic parameters, heat flux density, convective heat dissipation coefficient, heat flux distribution coefficient, and other thermodynamic parameters were calculated. Then, the numerical simulation of the temperature field of disc brake and the coupling analysis of thermal stress under different braking conditions were completed. At last, experimental results gave the analysis results of the temperature distribution characteristics of brake disc surface, and the comparison and demonstration of the finite element analysis were conducted.
\end{abstract}

\section{INTRODUCTION}

Brakes are the key components to ensure the driving safety of vehicles [1-4]. According to statistics of traffic accidents released by relevant departments, more than $30 \%$ of the driving accidents on slippery roads are related to vehicle sideslip or braking deviation caused by poor braking [5-7]. As people want the vehicles to be faster, it's required that the brakes should be able to absorb and dissipate heat in a shorter time, and better resist to the water fade phenomenon [8-11]. Due to the many merits listed above, disc brakes have been used more widely in vehicles that require high braking performance, especially large motor buses and trucks [12-13].

Chi et al. [14] constructed a 3D transient temperature-stress coupling calculation model for disc brakes with different structures under emergency braking conditions, and used it to simulate the braking process based on the finite element method. Yevtushenko and Kuciej [15] compared and analyzed the radial distribution of temperature field of disc brakes with different structures, calculated the peak thermal stress, and explored the impact of brake structure on the law of thermoelastic deformation and braking effect. Based on theories of heat transfer and tribology, in order to determine the loading method of thermal load, Evtushenko et al. [16] constructed a mathematical model of the heat transfer of disc brakes in finite element simulation software, and conducted simulation and experimental analysis on the distribution of transient temperature field of disc brakes under different loading conditions. Belhocine et al. [17] built a 3D thermalmechanical coupling finite element model of disc brakes, analyzed the thermal-coupling characteristics and frictional vibration characteristics of brakes under two modes of drag braking and start-stop braking, and explored the impact of different deceleration behaviors on thermal-mechanical coupling and vibration characteristics under the start-stop braking mode. Stevens and Tirovic [18] adopted the finite difference method to analyze the adiabatic state and thermal structure of disc brakes with cooling air duct, and obtained the braking heat distribution ratio under braking state and the distribution of temperature field and stress field.

Most existing literatures are numerical studies on temperature field and stress field of brakes with various structures, and they generally employed finite element analysis and simulation to study the braking process of brakes [19-26]. However, it's difficult to describe the failure problem of brakes under complex working conditions in only a few times of thermal-structural coupling simulations, so this paper attempts to analyze the coupling between temperature and thermal stress of disc brakes under multiple continuous braking conditions. The specific research contents are as follows: 1) Construct a 3D model of bus disc brake with a complex structure in ABAQUS; 2) Calculate the braking motion and dynamic parameters, heat flux density, convective heat dissipation coefficient, heat flux distribution coefficient, and other parameters; 3) Analyze the temperature field of disc brake based on numerical simulation method; 4) Perform thermal stress coupling analysis on disc brake under different braking conditions; 5) Obtain temperature distribution characteristics of brake disc surface through experiment, and complete the comparison and demonstration of finite element analysis.

\section{CONSTRUCTION OF THE FINITE ELEMENT MODEL OF DISC BRAKE}

The stable braking efficiency of disc brakes and its advantage in braking performance have met the requirements of passengers for safety and comfort, so they have been used more widely in recent years. When modeling disc brake in the 
finite element analysis software ABAQUS and analyzing it, it's necessary to set 5 kinds of boundary conditions for it, including: fixed initial boundary temperature, fixed ambient airflow temperature and convective heat transfer coefficient, the friction pair temperature field is only affected by heat conduction and heat convection, the material of the brake disc is isotropous, and the wear of brake disc is not considered.

Based on ABAQUS, this paper built a 3D model of bus disc brake with a complex geometric structure, meshed it using Hypermesh to control the density and size of the meshes to be within a reasonable range.

The vehicle braking process is actually the process of the vehicle to do work to overcome braking resistance and generate friction heat, wherein a large part of the generated friction heat is absorbed by the disc and friction pad of the brake, and a small part of the energy is absorbed by the ground. During the thermal stress coupling analysis of disc brakes, the heat flux density applied to the friction surface of brake disc can be equivalently regarded as the energy absorbed by the friction pair. Assuming: $Z_{G}$ represents the gravity of the vehicle when fully loaded, $K$ represents the wheelbase of the vehicle, $L_{Z}$ represents the height of the center of mass, and $d v / d \tau$ represents the rate of speed change when the vehicle is braking, then, the normal force of the front-axle wheels of the vehicle $F_{1}$ can be calculated using Formula 1:

$$
F_{1}=\frac{Z_{G}}{K}\left(K_{2}+\frac{L_{Z}}{z} \frac{d v}{d \tau}\right)
$$

The normal force of the rear-axle wheels of the vehicle $F_{2}$ can be calculated using Formula 2:

$$
F_{2}=\frac{Z_{G}}{K}\left(K_{1}+\frac{L_{Z}}{z} \frac{d v}{d \tau}\right)
$$

Assuming: $e(e=d v / d \tau)$ represents the braking intensity; $H_{G R 1}$ and $H_{G R 2}$ respectively represent the ground braking force of front and rear wheels, then the total ground braking force $H_{G R}$ of the vehicle during normal braking is the sum of inertial braking forces of the front and rear axles, that is:

$$
H_{G R}=H_{G R 1}+H_{G R 2}=\frac{Z_{G}}{z} \frac{d v}{d \tau}=Z_{G} e
$$

Assuming $\psi$ represents the adhesion coefficient, then the calculation formula of $H_{G R}$ is:

$$
H_{G R}=H_{\psi}=Z_{G} \psi=n \frac{d v}{d \tau}
$$

Formula 5 gives the formula for calculating the normal reactive force of the ground acting on the front wheels of the vehicle:

$$
F_{1}=\frac{Z_{G}}{K}\left(K_{2}+L_{z} \psi\right)
$$

The normal reactive force of the ground acting on the rear wheels of the vehicle is:

$$
F_{2}=\frac{Z_{G}}{K}\left(K_{1}+L_{z} \psi\right)
$$

The adhesive force of the front wheels of the vehicle can be calculated by Formula 7:

$$
\begin{aligned}
& H_{\omega 1}=\left(Z_{G} \frac{K_{2}}{K}+H_{G R} \frac{L_{z}}{K}\right) \cdot \psi \\
& =\frac{Z_{G}}{K}\left(K_{2}+\omega L_{z}\right) \psi
\end{aligned}
$$

The adhesive force of the rear wheels of the vehicle can be calculated by Formula 8:

$$
\begin{aligned}
& H_{\omega 2}=\left(Z_{G} \frac{K_{1}}{K}+H_{G R} \frac{L_{z}}{K}\right) \cdot \psi \\
& =\frac{Z_{G}}{K}\left(K_{1}+\omega L_{z}\right) \psi
\end{aligned}
$$

When the vehicle is fully loaded, the braking torque of front-axle brake wheels can be calculated by Formula 9:

$$
M O_{g 1}=H_{G R 1 \max } w_{f}=H_{\psi 1} w_{f}
$$

Similarly, under the same condition, the braking torque of rear-axle brake wheels can be calculated by Formula 10:

$$
M O_{g 2}=H_{G R 2 \max } w_{f}=H_{\psi 2} w_{f}
$$

When a vehicle is braking, if the front wheels lock first, the vehicle is prone to loss of steering control and braking deviation; and if the rear wheels lock first, it's prone to tail drift. Only by simultaneously locking the front and rear wheels under the maximum braking intensity can the vehicle lose its steering ability, this is a better braking situation, and the utilization of adhesion conditions of this braking method is the highest. Assuming: $H_{g 1}$ represents the braking force generated by front wheel brakes of the vehicle, $H_{G R 1}$ represents the braking force generated by the contact between front-axle wheels and the ground, then there is $H_{g 1}=H_{G R 1}=\psi C_{1} . H_{g 2}$ represents the braking force generated by rear wheel brakes of the vehicle, $H_{G R 2}$ represents the braking force generated by the contact between rear-axle wheels and the ground, then there is $H_{g 2}=H_{G R 2}=\psi C_{2}$. The expression for the braking method of locking the front and rear wheels at the same time is:

$$
H_{g 1}+H_{g 2}=H_{G R 1}+H_{G R 2}=\psi \cdot Z_{G}
$$

Assuming: $K_{1}$ and $K_{2}$ represent the distance from the center of mass of the vehicle to the front and rear axles, then there is:

$$
\frac{H_{g 1}}{H_{g 2}}=\frac{H_{G R 1}}{H_{G R 2}}=\frac{K_{2}+\psi L_{z}}{K_{1}-\psi L_{z}}
$$

Formula 13 gives the ratio $\alpha$ of the braking force of the front axle of vehicle to the total braking force: 


$$
\alpha=\frac{H_{g 1}}{H_{g}}=\frac{H_{g 1}}{H_{g 1}+H_{g 2}}
$$

By combining Formulas 12 and 13, we can get:

$$
\alpha=\frac{K_{2}+\psi L_{z}}{K}
$$

For the target bus studied in this paper, the distance from the center of mass of the vehicle to the front axle is $2.15 \mathrm{~m}$, the height of the center of mass is $0.95 \mathrm{~m}$, the adhesion coefficient takes a value of 700 , and the wheelbase of the vehicle is $6.25 \mathrm{~m}$, then Formula 15 can calculate the braking force distribution coefficient when the vehicle is fully loaded:

$$
\alpha=\frac{2.15+0.7 \times 0.8}{6.25}=0.4336
$$

Assuming $\mu_{0}$ represents the initial braking speed, $\delta$ represents the proportion of energy transferred to the brake disc, then the average braking power of a single front wheel can be calculated by Formula 16:

$$
G V=\frac{1}{2} \alpha \cdot \mu_{0} \cdot \delta \cdot \frac{Z_{G}}{z} \cdot \frac{d v}{d \tau}
$$

Assuming $F A$ represents the friction area, then the heat flux density could be calculated by Formula 17:

$$
D E_{l}=\frac{G V}{F A}
$$

When a vehicle is braking, heat transfer occurs between air and the surface of brake disc, that is, there's heat loss through convection between the two. When analyzing the convective heat dissipation process, if the rotate speed of brake disc changes, the convective heat transfer coefficient $\eta_{H C}$ changes accordingly. The convective heat dissipation between air and vent hole and the heat dissipation of the friction disc surface are the two primary heat dissipation methods that need to be considered for vent disc brakes. The heat dissipation method of solid disc brakes is mainly convective heat dissipation, and Formula 18 gives the empirical formula for calculating its convective heat transfer coefficient $\eta_{H C}$ :

$$
\eta_{H C}=\left\{\begin{array}{l}
0.70\left(\frac{\eta_{R D}}{E X}\right) \operatorname{Re}^{0.55}, \operatorname{Re} \leq 2.4 \times 10^{5} \\
0.04\left(\frac{\eta_{R D}}{E X}\right) \operatorname{Re}^{0.8}, \operatorname{Re}>2.4 \times 10^{5}
\end{array}\right.
$$

Assuming: $\eta_{R D}$ represents the thermal conductivity coefficient of the air; $E X$ represents the outer diameter of brake disc; $\theta$ represents the angular speed of brake disc; $\sigma_{R D}$ represents the air density; $\lambda_{R D}$ represents the air viscosity, $S H_{R D}$ represents the specific heat, and $R e=\theta \cdot \sigma_{R D} \cdot S H_{R D} / \lambda_{R D}$ represents the Reynolds number.

Vent disc brakes have both heat dissipation methods of heat dissipation through brake disc surface and heat dissipation through vent hole. Assuming $R e^{*}$ represents the Reynolds number, $F S_{d}$ represents the hydrodynamic diameter, $\mu_{A}$ represents the average airflow speed, $K$ represents the characteristic length of brake disc, and $T U_{P}$ represents the Prandtl number, then Formula 19 gives the formula for calculating $\eta_{H C}{ }^{*}$, namely the heat transfer coefficient of heat dissipation through vent hole of the vent disc brake:

$$
\eta_{H C}^{*}=\left\{\begin{array}{l}
\frac{3.72 \sqrt[3]{\left(\frac{\mathrm{Re}}{T U_{P}}\right)}\left(\frac{F S_{d}}{K}\right)^{0.83} \eta_{R D}}{F S_{d}}, \\
\operatorname{Re}^{*} \leq 10^{4} \\
0.46\left[1+\left(\frac{F S_{d}}{K}\right)^{0.83}\right] L_{n}^{0.8} T U_{P}^{0.33} \eta_{R D} \\
\frac{F S_{d}}{\operatorname{Re}^{*} \leq 10^{4}},
\end{array}\right.
$$

The corresponding Reynolds number $R e^{*}$ can be calculated by Formula 20:

$$
\operatorname{Re}^{*}=\frac{\mu_{A} \sigma_{R D} Z J_{d}}{\lambda_{R D}}
$$

Assuming: $d_{T F}$ represents the width of vent hole, $S_{Z D}$ represents the area of brake disc, then the hydrodynamic diameter $F S_{d}$ can be calculated by Formula 21:

$$
F S_{d}=\frac{2 d_{T F} E X_{i}\left(\frac{\omega E X_{0}}{360}-S_{Z D}\right)}{E X_{0}\left(d_{T F}+\frac{\omega E X_{0}}{360}-S_{Z D}\right)}
$$

The average airflow speed $\mu_{A}$ is:

$$
\mu_{A}=0.026 \theta \sqrt{E X_{0}^{2}-E X_{i}^{2}}\left(1+\frac{E X_{0}}{E X_{i}}\right)
$$

The characteristic length of brake disc $K$ is:

$$
K=\left(E X_{0}-E X_{i}\right) / 2
$$

By introducing parameters of the studied bus, we can get:

$$
\eta_{H C}^{*}=\left\{\begin{array}{l}
3.17 \sqrt[3]{\theta}, \theta \leq 22.32 \\
3.17 \sqrt[3]{\theta}, \theta>22.32
\end{array}\right.
$$

In summary, the convective heat dissipation coefficient of vent disc with both heat dissipation methods (disc surface heat dissipation and vent hole heat dissipation) is:

$$
\eta=\eta_{H C}+\eta_{H C}^{*}
$$


The convective heat transfer coefficient $\eta_{H C}$ is:

$$
\eta_{H C}=\left\{\begin{array}{l}
3.17 \theta^{0.55}+3.19 \sqrt[3]{\theta}, \theta \leq 22.32 \\
1.55 \theta^{0.8}+3.19 \sqrt[3]{\theta}, \theta>22.32
\end{array}\right.
$$

And the heat transfer coefficient of vent hole heat dissipation $\eta_{H C}{ }^{*}$ is:

$$
h_{c}=\left\{\begin{array}{l}
3.17 \times(34.27-14.1 t)^{0.55} \\
+3.17 \times \sqrt[3]{34.27-14.1 t} \quad 0 \leq t \leq 16 s \\
1.55 \times(34.27-14.1 t)^{0.8} \\
+3.17 \times \sqrt[3]{34.27-14.1 t} t>16 s
\end{array}\right.
$$

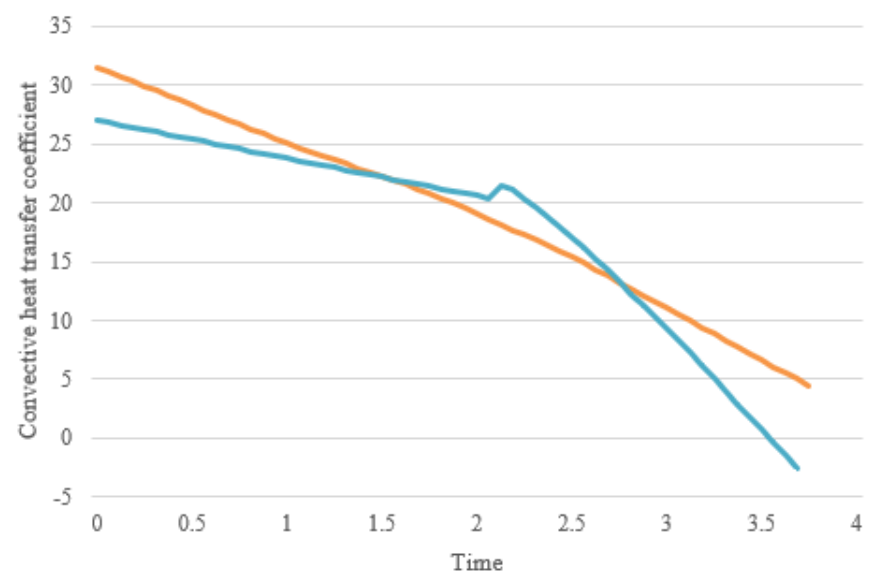

Figure 1. Fitting curve of convective heat dissipation of vent disc

Figure 1 shows the fitting curve of convective heat dissipation of vent disc. During the thermal stress coupling analysis of disc brake, it's assumed that the heat flow between air and brake contact surface is continuous and the average temperature is equal, then the total friction heat flow density $R L$ is equal to the sum of the heat flux density of friction pad $R L_{F D}$ and the heat flux density of brake disc $R L_{E D}$ :

$$
R L=R L_{F D}+R L_{E D}
$$

Assuming: $\beta$ represents the heat flux distribution coefficient, $\eta_{E D}$ represents the thermal conductivity coefficient of brake disc, $S H_{E D}$ represents the specific heat of brake disc, $\sigma_{E D}$ represents the density of brake disc, $\eta_{F D}$ represents the thermal conductivity coefficient of friction pad, $S H_{F D}$ represents the specific heat of friction pad, $\sigma_{F D}$ represents the density of friction pad, then the expression of the heat flux distribution coefficient is:

$$
\beta=\frac{R L_{E D}}{R L_{F D}}=\sqrt{\frac{\eta_{E D} S H_{E D} \sigma_{E D}}{\eta_{F D} S H_{F D} \sigma_{F D}}}
$$

Based on heat flux distribution coefficient $\beta$, the proportion of heat flux input to the friction pad can be calculated:

$$
g_{F D}=\frac{1}{1+\beta} \approx 0.1
$$

\section{SIMULATION ANALYSIS OF TEMPERATURE FIELD OF DISC BRAKE}

The changes in transient temperature of the friction contact area of brake disc during vehicle braking and the degree of thermal stress coupling are the main contents of the study on the distribution characteristics of temperature field in thermal stress coupling analysis of disc brakes. In this paper, the heat energy transfer during vehicle braking was calculated, the vehicle load was taken as the boundary condition that applies on disc brake surface to realize the simulation of temperature distribution of brake disc during braking processing and its change trend.

Based on the first law of thermodynamics, thermodynamic analysis of the brake disc was carried out. Assuming: $S Y_{Q}$ represents the heat energy of the system, $A C_{W}$ represents the work done, $\Delta E$ represents the internal energy, $\triangle E M$ represents the kinetic energy of the system, $\Delta S E$ represents the potential energy of the system, the disc brake is regarded as a closed system, and the total energy in the system remains constant all the time:

$$
S Y_{Q}-A C_{W}=\Delta E+\Delta E M+\Delta S E
$$

For the transient temperature field of disc brake, the rate of energy entering or leaving the system can be equivalent to the heat transfer efficiency of internal energy in the system. Assuming: $v_{0}$ represents the initial speed of the vehicle when braking, $v_{1}$ represents the final speed of the vehicle by the end of the braking process, $Q_{M}$ represents the mass of the vehicle, $g$ represents the gravitational acceleration, $\gamma$ represents the braking distance, $\chi$ represents the road slope coefficient and its sign (positive or negative) is determined by the state of the ramp, $\varepsilon$ represents the rolling resistance coefficient, and Formula 32 gives the vehicle kinetic energy conversion formula during vehicle braking:

$$
S Y_{Q}=\frac{1}{2} Q_{M} v_{0}^{2}-\frac{1}{2} Q_{M} v_{1}^{2}+Q_{M} g( \pm \chi-\varepsilon) \gamma
$$

Heat conduction, heat convection, and heat radiation are the main heat transmission modes in vehicle braking process, wherein heat radiation has little effect on the temperature change of brake disc in the actual analysis process, so it can be ignored.

The heat transfer parameters of the model were determined by heat flux density, convective heat transfer coefficient, and initial ambient temperature. Taking time as the reference system, loads were applied in the thermal analysis unit of ANSYS, and the loading step was set to $0.2 \mathrm{~S}$.

When performing transient thermal analysis on the disc, heat flux density boundary conditions related to time change should be introduced, using the change of heat flux density, calculations could be carried out based on the limit conditions of braking and the specific attributes of the vehicle. Assuming $T R$ represents the conversion rate between kinetic energy and thermal energy, $G H$ represents the axle load, $B A$ represents the braking acceleration, $m$ represents the number of single axle 
brake discs, $J_{N}$ and $J_{W}$ represent the inner and outer diameters of friction contact, then the value of heat flux density $R L(\tau)$ at time moment $\tau$ can be calculated by Formula 33:

$$
R L(\tau)=T R \frac{-G H(B A)^{2} \tau+G H \cdot v_{0} \cdot B A}{2 m \pi\left(J_{W}{ }^{2}-J_{N}{ }^{2}\right)}
$$

Assuming: $v$ represents the vehicle speed, $\Phi$ represents the empirical formula coefficient, then Formula 34 gives the calculation formula of convective heat transfer coefficient during transient thermal analysis of the disc:

$$
\eta_{S}=0.92+\Phi v * \exp (-v / 328)
$$

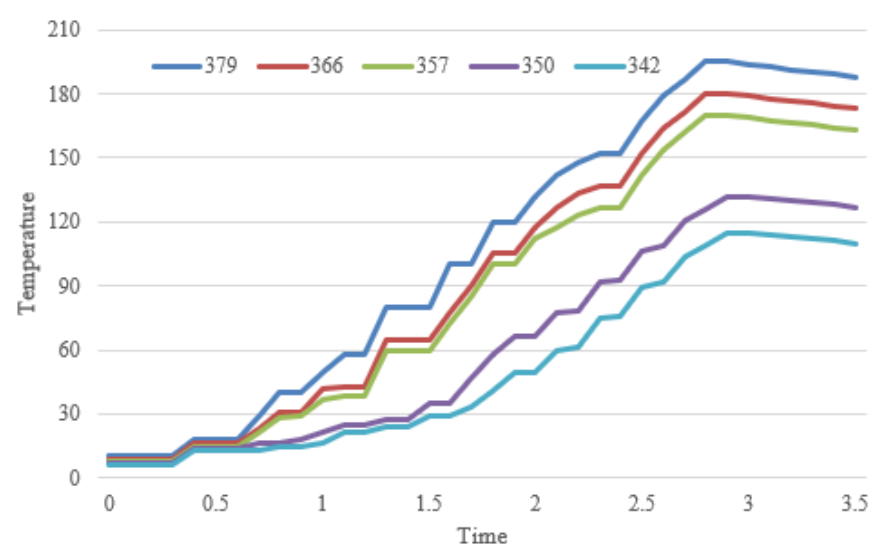

(a)

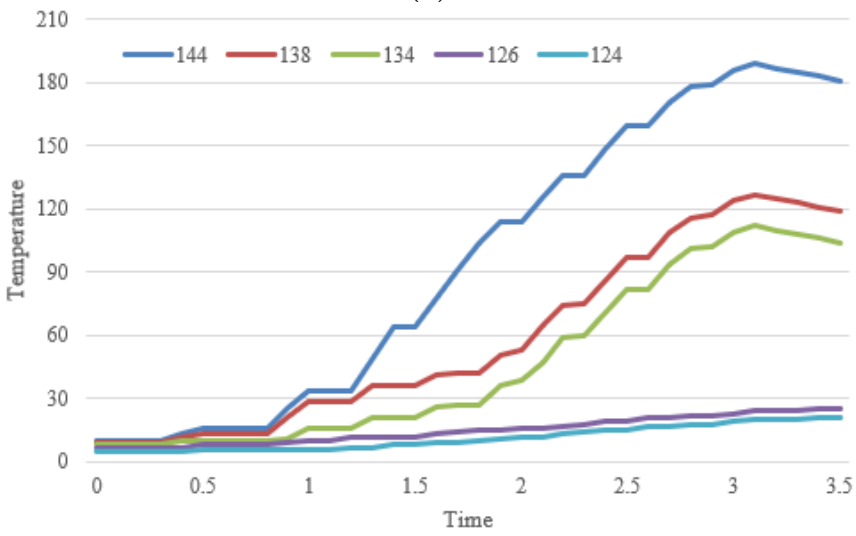

(b)

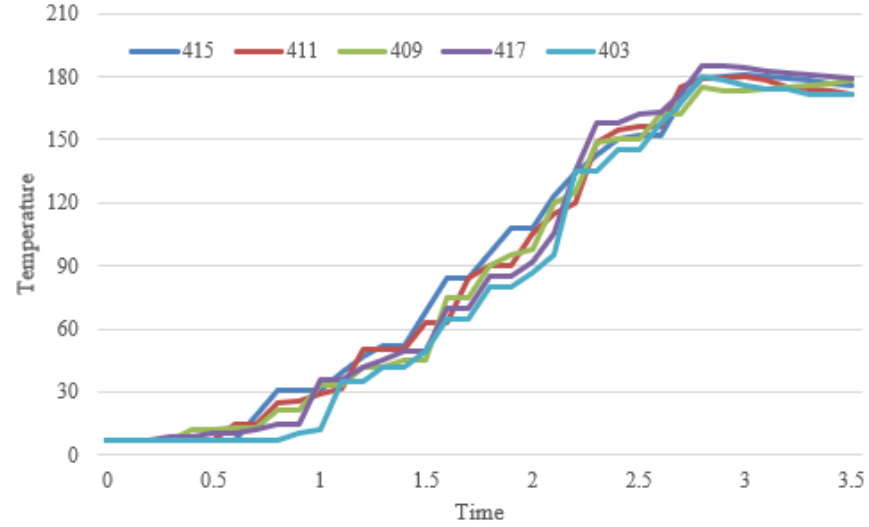

(c)

Figure 2. Distribution of radial, axial and circumferential temperature of the brake disc
Figure 2 (a), (b), and (c) respectively show the distribution of radial, axial, and circumferential temperature of the brake disc. According to the curve of radial temperature, the overall temperature changes in the contact area of brake disc exhibited characteristics of zigzag rise first and decline later. At nodes at the inner and outer sides of the brake disc, there're obvious differences in the maximum temperature in the radial direction, and the maximum temperature difference reached $109.1^{\circ} \mathrm{C}$. According to the curve of axial temperature, under the joint action of friction heat generation and heat conduction, due to the effect of heat flux input, the temperature values at nodes on the disc contact surface all fluctuated greatly, while the change trend of temperature inside the disc formed by the temperature diffusion of component structure showed down, and the maximum internal temperature was far lower than the maximum surface temperature. According to the curve of circumferential temperature, different circumferential nodes at a same radius position showed little difference in temperature, and there's a certain temperature gradient and time lag. At the radial, axial and circumferential nodes farther away from the braking contact area, the temperature change was not obvious because of the weak temperature diffusion effect.

\section{THERMAL STRESS COUPLING ANALYSIS OF DISC BRAKE}

The coupling between temperature field and stress field of brake disc during vehicle braking is a complex process. In order to figure out the correlation between the two under thermal stress coupling state, this paper constructed a friction contact model of friction pad and brake disc to simulate the moving heat source based on their relative sliding.

Assuming: the road condition of the contact ground surface is ordinary concrete with an adhesion coefficient $\psi_{F D}$ of 0.8 , because $e \cdot L_{z}=d v / d \tau=\psi_{F D} \cdot L_{z}$, then at this time, the maximum normal reactive force generated by the ground acting on a single-side tire during vehicle braking is:

$$
F_{\max }=\frac{Z_{G}}{K}\left(K_{2}+0.8 L_{z}\right)
$$

Bringing relevant parameters, it could be calculated that $F_{\max }$ was $13256.24 N$. Considering the peak value $\psi_{F D}$, the maximum vehicle braking force corresponding to the concrete ground could be calculated further:

$$
\begin{aligned}
& H_{E B-\max }=F_{\text {max }} \cdot \frac{\psi_{F D}}{2} \\
& =0.4 \times 13256.24 \mathrm{~N}=5302.5 \mathrm{~N}
\end{aligned}
$$

Assuming: the rolling radius of the tire $J_{r}$ is $0.3 \mathrm{~m}$, then the maximum braking torque can be calculated based on Formula 37:

$$
\begin{aligned}
& L J_{\text {max }}=H_{E B-\max } \cdot J_{r} \\
& =0.3 \times 5302.5 \mathrm{~N}=1590.7 \mathrm{~N}
\end{aligned}
$$

Assuming: the initial speed of the vehicle is $120 \mathrm{~km} / \mathrm{h}$, the braking pressure and braking time are $3.5 \mathrm{MPa}$ and $4.5 \mathrm{~s}$ respectively, then the initial rotate speed of the disc was calculated to be $87.45 \mathrm{rad} / \mathrm{s}$. In this paper, under a $3.7 \mathrm{MPa}$ 
braking pressure, the maximum braking pressure was selected at $0.0012 \mathrm{~s}$, and the braking duration was determined to be $4.5 \mathrm{~s}$, then they were substituted into formulas to obtain the parameter values.

\section{EXPERIMENTAL RESULTS AND ANALYSIS}

Based on the constructed 3D finite element model of disc brake, heat flux density and other parameters, and various boundary conditions, the disc of the disc brake was simulated in $A B A Q U S$ to reveal the variation laws of transient temperature and quasi-static stress of each part of the disc.

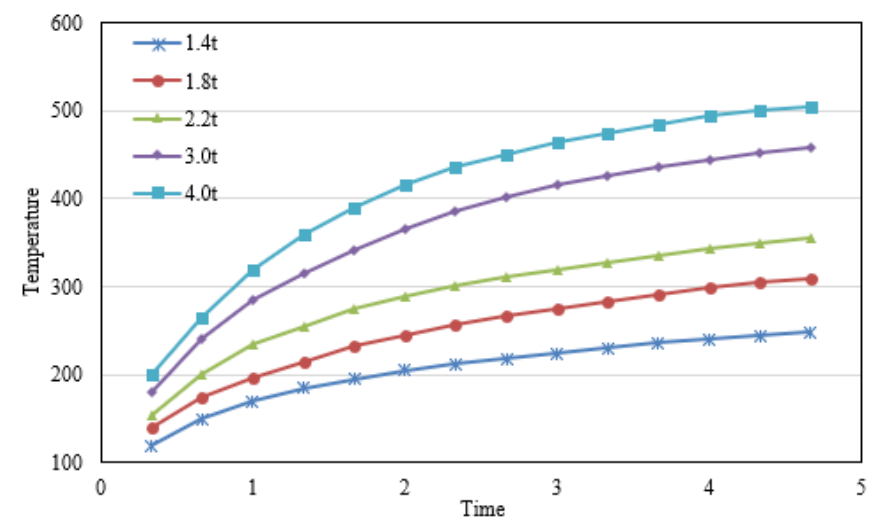

(a)

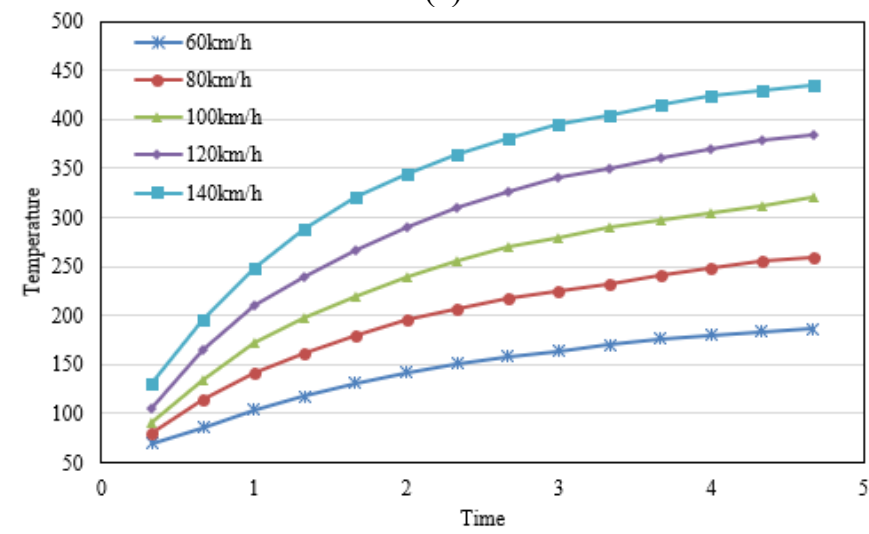

(b)

Figure 3. Comparison of brake disc temperature under different loads and initial speeds

The initial braking speed of the bus was set to be $90 \mathrm{~km} / \mathrm{h}$, and the load capacity of the bus was set with a few different values between 1.4t-4t, then Figure 3(a) shows the corresponding changes of the maximum temperature of the disc, according to the figure, the maximum temperature of the disc rises with the increase of load. This is because within the short braking time, the input heat flux density increases approximately linearly with the increase of load, thus the maximum temperature of the brake disc surface has an approximately linear relationship with the load of the bus. Moreover, the load capacity of the bus was fixed, and the initial braking speed of the bus was set with a few different values between $60 \mathrm{~km} / \mathrm{h}-140 \mathrm{~km} / \mathrm{h}$, then Figure $3(\mathrm{~b})$ shows the changes of disc temperature under different initial braking speeds. According to the figure, compared with the impact of initial speed on the maximum temperature of the disc, the impact of load is greater, and this obtained conclusion is consistent with the actual situation.

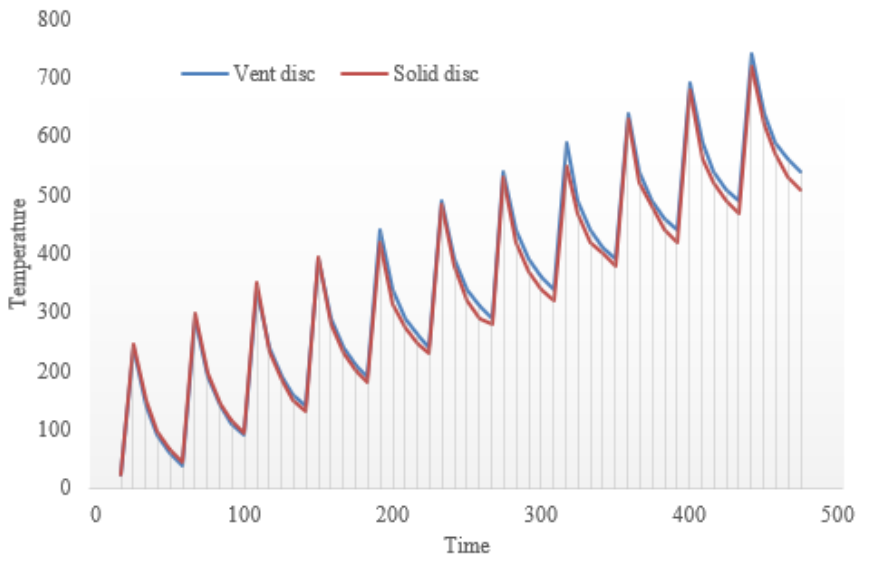

Figure 4. The curve of the maximum temperature of disc under multiple brakes

For brake discs of two different structures, vent disc and solid disc, their temperature field under multiple brakes was simulated respectively, and curves are shown in Figure 4, as can be seen from the figure, in the non-braking stage without heat flux density input, under the action of heat conduction and convective heat dissipation, the contact area between a solid disc and air was smaller than that between a vent disc (with vent openings) and air, so the maximum temperature of vent disc was lower.

Table 1. Analysis of estimation errors

\begin{tabular}{cccccc}
\hline \multirow{2}{*}{ Experiment } & \multicolumn{2}{c}{$\begin{array}{c}\text { Thickness Braking } \\
\text { of disc }\end{array}$} & \multicolumn{2}{c}{$\begin{array}{c}\text { Maximum } \\
\text { intensity }\end{array}$} & \multicolumn{2}{c}{$\begin{array}{c}\text { Maximum Maximum } \\
\text { equivalent } \\
\text { stress }\end{array}$} & $\begin{array}{c}\text { braking } \\
\text { torque }\end{array}$ \\
\hline 1 & 13.086 & 6.791 & 195.498 & 185.289 & 1273.654 \\
2 & 11.671 & 13.365 & 192.815 & 187.466 & 1276.895 \\
3 & 13.284 & 9.556 & 185.657 & 192.925 & 1325.195 \\
4 & 13.847 & 9.191 & 184.652 & 195.412 & 1108.565 \\
5 & 13.865 & 9.563 & 181.894 & 189.891 & 1127.912 \\
6 & 11.969 & 12.157 & 186.359 & 196.714 & 1135.750 \\
7 & 12.156 & 13.782 & 182.153 & 197.165 & 1254.894 \\
\hline
\end{tabular}

The real values and estimated values of 7 experimental sample points were analyzed, the corresponding estimation errors are given in Table 1, and the error analysis of the approximate model of maximum temperature, maximum braking torque, and maximum equivalent stress is given in Figure 5. The optimized mathematical model obtained based on the analysis results can replace the complex finite element model for the temperature-thermodynamic coupling analysis of the disc brake.

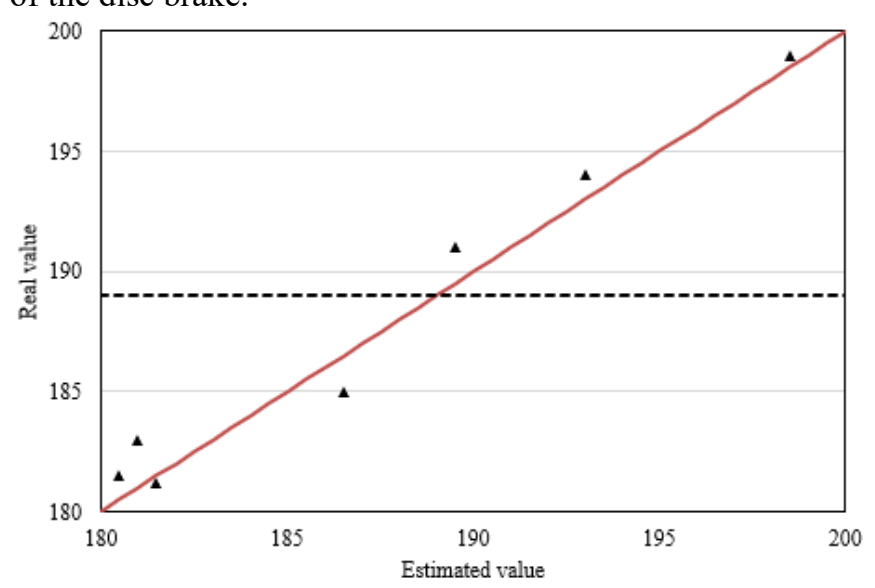

(a) 


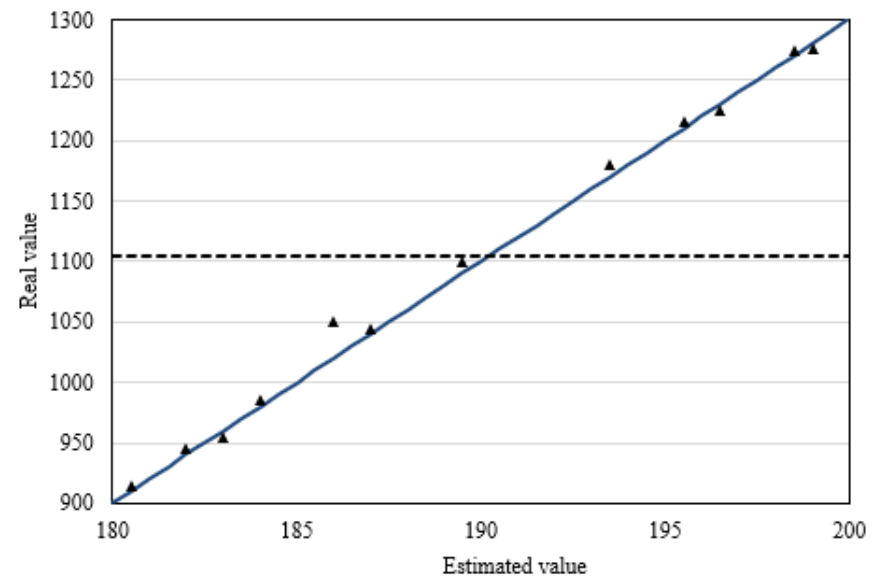

(b)

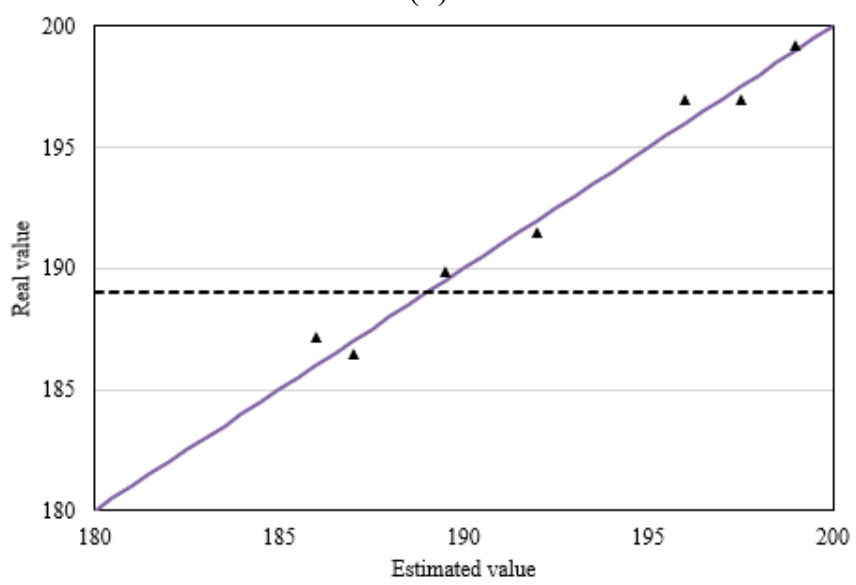

(c)

Figure 5. Error analysis of the approximate model of maximum temperature, maximum braking torque, and maximum equivalent stress

In this paper, the maximum temperature, maximum braking torque, and maximum equivalent stress of brake disc were taken as constraint functions for the iterative optimization of the mathematical model. To ensure reliable optimization variables obtained from the optimized mathematical model, the optimization variables need to be substituted into the finite element analysis model for simulation and calculation, and to ensure the effectiveness of model iteration through comparative demonstration.

Table 2. Comparison of real values, estimated values, and simulated values

\begin{tabular}{ccccc}
\hline & $\begin{array}{c}\text { Real } \\
\text { value }\end{array}$ & $\begin{array}{c}\text { Optimized } \\
\text { solution value }\end{array}$ & $\begin{array}{c}\text { Simulated } \\
\text { value }\end{array}$ & $\begin{array}{c}\text { Experimental } \\
\text { value }\end{array}$ \\
\hline $\begin{array}{c}\text { Maximum } \\
\text { temperature }\end{array}$ & 183.5 & 186.651 & 188.34 & 198.7 \\
$\begin{array}{c}\text { Maximum } \\
\text { braking torque } \\
\text { Maximum } \\
\text { equivalent } \\
\text { stress }\end{array}$ & 1351.42 & 1478.45 & 1435.26 & 1541.68 \\
\hline
\end{tabular}

Table 2 compares the real values, estimated values, and simulated values of the maximum temperature, maximum braking torque, and maximum equivalent stress of the brake disc. According to the data in the table, the optimized model can well meet the performance optimization indicators of the disc brake of bus braking system. The errors between simulated values, estimated values, and experimental results were relatively ideal, which had verified the feasibility and accuracy of the optimized model, and can provide references and ideas for the design of bus braking system in the future. Table 3 gives a comparison of the structural parameters of brake disc, and its structure was adjusted in terms of 3 parameters of the number of vent openings, the height of vent openings, and the proportion of central angles.

Table 3. Structural parameters of vent brake disc

\begin{tabular}{cccc}
\hline Group & $\begin{array}{c}\text { Number of } \\
\text { vent } \\
\text { openings }\end{array}$ & $\begin{array}{c}\text { Height of } \\
\text { vent } \\
\text { openings }\end{array}$ & $\begin{array}{c}\text { Proportion of } \\
\text { central angles }\end{array}$ \\
\hline 1 & 30 & 15 & $5 / 12$ \\
2 & 30 & 15 & $6 / 12$ \\
3 & 30 & 15 & $7 / 12$ \\
4 & 34 & 15 & $7 / 12$ \\
\hline 1 & 20 & 15 & $6 / 12$ \\
2 & 26 & 15 & $7 / 12$ \\
3 & 30 & 15 & $7 / 12$ \\
4 & 34 & 15 & $6 / 12$ \\
\hline 1 & 30 & 14 & $6 / 12$ \\
2 & 30 & 15 & $6 / 12$ \\
3 & 30 & 16 & $6 / 12$ \\
4 & 30 & 17 & $6 / 12$ \\
\hline
\end{tabular}

To further figure out the degree of impact of the three parameters on the maximum temperature of brake disc, this study designed an orthogonal experiment, and its specific scheme and results are given in Table 4 . The range values of the three parameters (number of vent openings, height of vent openings, proportion of central angles) were 26.5, 5.40, and 7.5 respectively. Therefore, from large to small, the impact weights of the three parameters on brake disc temperature were: number of vent openings, proportion of central angles, and height of vent openings. The brake disc model structure under the combination of $6 / 12$ central angle proportion, $15 \mathrm{~mm}$ vent opening height and 34 vent numbers was the best.

Table 4. Scheme and results of the orthogonal experiment

\begin{tabular}{ccccc}
\hline \multicolumn{2}{c}{ Experiment } & $\begin{array}{c}\text { Number of } \\
\text { vent } \\
\text { openings }\end{array}$ & $\begin{array}{c}\text { Height of } \\
\text { vent } \\
\text { openings }\end{array}$ & \multicolumn{2}{c}{$\begin{array}{c}\text { Proportion of Experimental } \\
\text { central angles }\end{array}$} & results \\
\hline 1 & 1 & 1 & 1 & 643.5 \\
2 & 2 & 1 & 1 & 631.2 \\
3 & 3 & 1 & 1 & 627.6 \\
4 & 4 & 2 & 1 & 645.3 \\
5 & 2 & 1 & 2 & 625.1 \\
6 & 2 & 3 & 2 & 631.6 \\
7 & 1 & 2 & 3 & 642.9 \\
8 & 4 & 2 & 3 & 634.5 \\
9 & 2 & 2 & 2 & 646.3 \\
10 & 1 & 4 & 1 & 637.8 \\
Mean 1 & 634.625 & 634.540 & 627.300 & \\
Mean 2 & 628.850 & 627.315 & 629.500 & \\
Mean 3 & 641.520 & 637.865 & 632.100 & \\
Mean 4 & 632.600 & 631.100 & 635.400 & \\
Range & 26.500 & 5.400 & 7.600 & \\
\hline
\end{tabular}

\section{CONCLUSION}

This paper conducted temperature-thermal stress coupling analysis on disc brake under multiple continuous braking conditions. At first, a 3D model of bus disc brake was built in 
ABAQUS, and its thermodynamic parameters were calculated. Then, numerical simulation of the temperature field of disc brake was conducted and the thermal stress coupling under different braking conditions was analyzed. In this paper, the finite element analysis software ABAQUS was adopted to simulate the disc of the disc brake, and the variation laws of the transient temperature and quasi-static stress of each part of the disc were obtained. After that, experimental results compared the changes of disc temperature under different loads and initial speeds, and diagrams of error analysis of the approximate model of maximum temperature, maximum braking torque, and maximum equivalent stress were plotted. At last, the feasibility and accuracy of the optimized model were verified by experimental results, which could provide references and ideas for the design of bus braking system in the future.

\section{ACKNOWLEDGEMENT}

Science and Technology Research Project of Jiangxi Provincial Department of Education (Grant No.: GJJ211909).

\section{REFERENCES}

[1] Varecha, D., Kohár, R., Lukáč, M. (2021). Theoretical study of heat conduction in the multi-disc brake integrated into the drive wheel AGV during braking. Bulletin of the Polish Academy of Sciences: Technical Sciences, e136718-e136718. https://doi.org/10.24425/bpasts.2021.136718

[2] Zhang, Y., Jin, X., He, M., Wang, L., Wang, Q., Wang, L., $\mathrm{Wu}, \mathrm{Y}$. (2017). The convective heat transfer characteristics on outside surface of vehicle brake disc. International Journal of Thermal Sciences, 120: 366-376. https://doi.org/10.1016/j.ijthermalsci.2017.06.020

[3] Kuciej, M. (2011). Accounting changes of pressure in time in one-dimensional modeling the process of friction heating of disc brake. International Journal of Heat and Mass Transfer, 54(1-3): 468-474. https://doi.org/10.1016/j.ijheatmasstransfer.2010.09.023

[4] Tirovic, M., Galindo-Lopez, C.H. (2008). Convective heat dissipation from a wheel-hub-mounted railway brake disc. Proceedings of the Institution of Mechanical Engineers, Part F: Journal of Rail and Rapid Transit, 222(4):

355-365. https://doi.org/10.1243/09544097JRRT135

[5] Topouris, S., Stamenković, D., Olphe-Galliard, M., Popović, V., Tirovic, M. (2020). Heat dissipation from stationary passenger car brake discs. Strojniski Vestnik/Journal of Mechanical Engineering, 66(1): 1528.

[6] Yan, H., Wu, W.T., Feng, S., Xie, G. (2018). Role of vane configuration on the heat dissipation performance of ventilated brake discs. Applied Thermal Engineering, 136: $118-130$ https://doi.org/10.1016/j.applthermaleng.2018.03.002

[7] Harada, N., Tanida, Y., Fukuda, T., Takuma, M., Tsujikawa, M., Higashi, K. (2016). Development of cast steel brake disc with heat shock resistance. 72nd World Foundry Congress, WFC 2016, 66-67.

[8] Koranteng, K., Shaahu, J.S., Yi, Y.B. (2020). Transient Heat Transfer Simulation and Buckling Analysis of Disc
Brakes in In-Wheel Motor-Driven Vehicles, 2020-011618. https://doi.org/10.4271/2020-01-1618

[9] Yevtushenko, A., Kuciej, M., Och, E., Yevtushenko, O. (2018). Frictional heating of the brake disc with essential nonlinearity thermal barrier coating. International Communications in Heat and Mass Transfer, 95: 210-216. https://doi.org/10.1016/j.icheatmasstransfer.2018.05.01 0

[10] Ghadimi, B., Kowsary, F., Khorami, M. (2015). Heat flux on-line estimation in a locomotive brake disc using artificial neural networks. International Journal of Thermal Sciences, 90: 203-213. https://doi.org/10.1016/j.ijthermalsci.2014.12.012

[11] Yevtushenko, A.A., Grzes, P. (2015). 3D FE model of frictional heating and wear with a mutual influence of the sliding velocity and temperature in a disc brake. International Communications in Heat and Mass Transfer, 62: 37-44.

[12] Bilgic Istoc, S., Winner, H. (2018). A new model describing the formation of heat cracks in brake discs for commercial vehicles. SAE Technical Papers, October 5, 2018, rake Colloquium and Exhibition - 36th Annual, BRAKE 2018.

[13] Istoc, S.B., Winner, H. (2018). Simulation concept for the forecast of heat crack formation in truck brake discs on the inertia dynamometer. VDI Berichte, 2018(2333): 571-583.

[14] Chi, Z., He, Y., Naterer, G. (2009). Convective heat transfer optimization of automotive brake discs. SAE International Journal of Passenger Cars-Mechanical Systems, 2(2009-01-0859): 961-969. https://doi.org/10.4271/2009-01-0859

[15] Yevtushenko, A.A., Kuciej, M. (2009). Temperature in a frictionally-heated ceramic-metal patch and cast iron disc during braking. Numerical Heat Transfer, Part A: Applications, 56(2): 97-108. https://doi.org/10.1080/10407780903106925

[16] Evtushenko, A.A., Ivanik, E.G., Konechny, S. (1998). Determination of the effective heating depth of the disc brake pad. Trenie i Iznos, 19(3): 318-322.

[17] Belhocine, A., Wan, Z.W.O. (2018). Computational fluid dynamics modeling and computation of convective heat coefficient transfer for automotive disc brake rotors. Comput Therm Sci, 10(1): 1-21.

[18] Stevens, K., Tirovic, M. (2018). Heat dissipation from a stationary brake disc, Part 1: Analytical modelling and experimental investigations. Proceedings of the Institution of Mechanical Engineers, Part C: Journal of Mechanical Engineering Science, 232(9): 1707-1733.

[19] Tirovic, M., Stevens, K. (2018). Heat dissipation from a stationary brake disc, Part 2: CFD modelling and experimental validations. Proceedings of the Institution of Mechanical Engineers, Part C: Journal of Mechanical Engineering Science, 232(10): 1898-1924. https://doi.org/10.1177/0954406217707984

[20] Pan, G., Cai, R. (2018). Thermal stress coupling analysis of ventilated disc brake based on moving heat source. Advances in Materials Science and Engineering, 2018. https://doi.org/10.1155/2018/8162028

[21] Carmona, S., Rouizi, Y., Quéméner, O., Joly, F., Neveu, A. (2018). Estimation of heat flux by using reduced model and the adjoint method. Application to a brake disc rotating. International Journal of Thermal Sciences, 131:

94-104. 
https://doi.org/10.1016/j.ijthermalsci.2018.04.036

[22] Belhocine, A., Omar, W. (2018). CFD analysis of the brake disc and the wheel house through air flow: Predictions of Surface heat transfer coefficients (STHC) during braking operation. Journal of Mechanical Science \& Technology, 32(1): 481-490.

[23] Yevtushenko, A., Grzes, P. (2011). Finite element analysis of heat partition in a pad/disc brake system. Numerical Heat Transfer, Part A: Applications, 59(7): 521-542. https://doi.org/10.1080/10407782.2011.561098

[24] Yevtushenko, A., Kuciej, M., Topczewska, K. (2020). Frictional heating during braking of the $\mathrm{C} / \mathrm{C}$ composite disc. Materials,

13(12):

2691. https://doi.org/10.3390/ma13122691

[25] Jian, Q., Wang, L., Shui, Y. (2020). Thermal analysis of ventilated brake disc based on heat transfer enhancement of heat pipe. International Journal of Thermal Sciences, 155:

106356. https://doi.org/10.1016/j.ijthermalsci.2020.106356

[26] Yevtushenko, A., Kuciej, M. (2020). A method to account for thermal sensitivity and friction heat resistance of materials in calculating disc brake temperature mode. Journal of Friction and Wear, 41(3): 221-227. https://doi.org/10.3103/S1068366620030058 